\title{
Zoltan Bun
}

\section{Between Analogue and Digital Diagrams}

\section{Zoltan Bun}

Architect, PhD student

Faculty of Architecture,

University of Technology and Economics

Budapest, Hungary

bunzoltan@gmail.com 


\title{
Zoltan Bun
}

\section{Between Analogue and Digital Diagrams}

\begin{abstract}
This essay is about the interstitial. About how the diagram, as a method of design, has lead from the analogue deconstruction of the eighties to the digital processes of the turn of the millennium. Specifically, the main topic of the text is the interpretation and the critique of folding (as a diagram) in the beginning of the nineties. It is necessary then to unfold its relationship with immediately preceding and following architectural trends, that is to say we have to look both backwards and forwards by about a decade. The question is the context of folding, the exchange of the analogue world for the digital. To understand the process it is easier to investigate from the fields of art and culture, rather than from the intentionally perplicated ${ }^{1}$ thoughts of Gilles Deleuze. Both fields are relevant here because they can similarly be used as the yardstick against which the era itself it measured. The cultural scene of the eighties and nineties, including performing arts, movies, literature and philosophy, is a wide milieu of architecture. Architecture responds parallel to its era; it reacts to it, and changes with it and within it. Architecture is a medium, it has always been a medium, yet the relations are transformed. That's not to say that technical progress, for example using CAD-software and CNC-s, has led to the digital thinking of certain movements of architecture, (it is at most an indirect tool). But the 'up-to-dateness' of the discipline, however, a kind of non-servile reading of an 'applied culture' or 'used philosophy'2 could be the key.
\end{abstract}

We might recall here, parenthetically, the fortunes of the artistic in contemporary mass society. The proliferation of museums, the magnification of the figure of the artist, the existence of a massive consumption of printed and televised artistic images, the widespread appetite for information about the arts, all reflect, of course, an increasingly leisured society, but also relate precisely to the fact that, faced with the tedium of everyday, real, lived experience, of the scientific illusion, of work and production, the world of art appears as a kind of last preserve of reality, where human beings can still find sustenance. Art is understood as being a space in which the fatigue of the contemporary subject can be salved away. $)^{3}$

\section{Cultural embediment}

We must also consider those significant historical-political changes that took place during the examined time. From a certain point of view, both Central and Eastern Europe were responsible for the death of postmodern feeling. The world which had been divided into three parts, or let's call it a 'three-fold world', at one stroke became dual but without a counterpart, without an alternative that had existed more or less in the image of socialism. The Promised Land seemed to be guaranteed by liberal democracy. The 'double code', a privilege of the Western world, immediately belonged to everybody. The whole of the East accepted it, it had to be accepted

11 - ARCC Journal / Volume 5 Issue 2 - 11 
with all the attached factors (capitalism and ideology) in a big system-package ${ }^{4}$. In this endless pluralism, in the 'end of history', it was not an option to separate politics from economy, arts from society, even architecture from culture. It could have result in a kind of singularity of the individual: the respect of alternative lifestyles, ways of thinking and 'otherness' held the promise of very heterogeneous societies. Then it was obvious, or rather a commonplace, to consider this unified world as a field of contradictions. Confronting ourselves with the oppositions of totalization and freedom, uniformity and pluralism, global and local, is inevitably embarrassing. That is why artists and theorists use a contrasting method of criticism instead of creating an ordered one.

Meanwhile there is no doubt that the electronic had exceeded the old mechanic spirit and had dominated culture, and in recent years the same has happened with the digital over the electronic. So parallel with the above-mentioned annulling of the absolute reference points in thinking, its image in art disconnected from reality. The non-closed and incomplete world cannot be represented anymore. In the 'post-classical' era everything, hence image and architecture is information that cannot be shaped by traditional tools. That is why it is very important to seek for new forms.

Until the end of the 1980s, in thinking as in the material territory, the whole world was constructed from single elements that barely changed or transformed for thousands of years. The creating technique was to do nothing other than to superpose or juxtapose these parts to an integration from ancient times to postmodernism. Jeffrey Kipnis affirmed in the early 1990s that it was said that we have 'exhausted the possibilities of forms', we can only choose from the received catalogue of them: 'It seems to me that every indication [of form] today is to the contrary; whether one considers the political transformations in Eastern Europe or the technological transformations that characterise today's society. The building of the catalogue of available forms, aesthetic forms, institutional forms and of forms of social arrangement, has only just begun.' 6 Hence extensive research has to be undertaken based on the fundamental metamorphosis of understanding history, politics and economy. This research started more easily in other disciplines of art and resulted in 'contemporary answers'. In the second half of the twentieth century, in opposition to the 'empty plot' of modernism, archeology seemed to be a relevant device to withstand uniformity and make a kind of continuous history. Michel Foucault and Jacques Derrida explained the world as historical and cultural layers heaped one on top of the other and they regarded the 'actual present' as rereading and restructuring the system. This build-up contained then traces from the past, all known pieces in new relationships. So coming closer to the turn of the millennium, searching for any kinds of new forms (figures, frames, structures, programs, etc.) inevitably has to supersede superposing existing systems, even deconstruction, the last layering hero. Therefore in the nineties it was a declared purpose, during alternating decon, to kill the collage. Gilles Deleuze's rhizomatic thinking and folded forms appeared to be adequate to achieve this goal. Both of them, deconstruction and folding, were warriors against the territory of depleted clichés and conformism. They fought on the same side, but while the first was limited ('to a particular order of semiotic recombinations'7) and was not able to manage its power over its heterogeneity, the latter was trained against a bunch of enemies to maintain a seem-to-be-organic, complex empire that was still constructed from existent contexts.

12 - ARCC Journal / Volume 5 Issue 2 - 12 
According to the popular pendulum or spiral metaphor of cultural theory, the angular shape of decon needed to be followed by the round shape of folding: simplifying art history and reducing it to pure form, a cyclical method can be discovered over the centuries. Eras, styles and then trends were swinging from one pole to the other. As Mario Carpo stated in the nineties, after the strict, sharp, angular forms of decon, the smooth and curved 'dominated industrial design, fashion, furniture, body culture, car design, food, critical theory in the visual arts, sex appeal, the art of discourse, even architecture's. So the change is not questionable from this point of view, it was necessary to smelt the old warrior into a brand new structure of a flowing mass. And there is another cyclical theory of structure or the shape of structures, similar to manmade forms: a differentiated, shown or visible system (decon) and an integrated, hidden or invisible one (folding) alternate with each other. But the cultural metamorphosis near to nowadays is not just about form or structure; these are only some of the results of changing paradigms. The shift from the stable, unambiguous, solid space to the pulsating, always-becoming, event-based media space has influenced and has been influenced by architecture, as well as other disciplines. All of them are dissolved in a huge net, a rhizomatic system, the above-mentioned space-model. This process started with the theoretical deconstruction of the existing elements, blowing them up and trying to create a new structure, but partially using old methods like collage. Folding therefore wanted to reconfigure the pieces into an anti-classical new whole, but partially in the old, 'real' world.

\section{Deconstructing history}

Deconstruction asked questions about basis and structure, about the forces that keep the system together. It criticized and argued all existing and dominating structures and books of rules, not with the intention of erasing them, but to re-evaluate and twist them. Questioning is the most significant motive behind deconstruction: uncovering traces and relationships from the past, while always also questioning the discipline itself. During the investigation of roots or traces it performs a double operation: it pulls down the essence of the genre and rebuilds it in a different manner. This dislocation is the 'de-construction' that forms the core of the problem and does not even try to search for a way out from it. The privative prefix indicates that it is not a new construction that is emerging from the existing one but the slipping of the meaning and absolute presence of the previous system. Parallel with this, absence, the lack of embodiment of that which previously existed, is pushing itself into the spotlight. One can say from this point of view that deconstruction on the one hand is buried inside itself, and on the other, it is extremely decadent. It is not suited to anything else but criticising against already-made objects, so it is far away from fertility, from any kind of productivity of novelty, unless the process is not directed towards creating absences which define the new in terms of the old. It was able to rethink the tradition of western philosophy and history so was able to do with any structure built on it: it transformed these systems by dislocating hierarchy and binary contradictions and twisting causality.

It is not our task in this paper to describe the transposition of deconstruction from philosophy to architecture or architecture theory. Simplifying the process it can be stated that if philosophy, constructed mainly from the notions of building, can be deconstructed, then this would lead to

13 - ARCC Journal / Volume 5 Issue 2 - 13 
a reaction on the original construction: architecture. Deconstruction as a manner in architecture (and in $\mathrm{art}^{9}$ ) led to a criticism of modernity that was new and totally different from the former theories. It was abstract and semi-dependent on context at the same time, it was able to reconsider the modern tradition and to immerse itself in centuries of art history ${ }^{10}$. Deconstructing architecture does not necessarily or primarily mean building but the reviewing of the role, the meaning and the relationships of the principle and of the architect.

This kind of thinking dared to face up to the heterogeneity and pluralism of the era, as well as to the instability or uncertainty that was promised without any doubt by the present. This courage and honesty labelled deconstruction as negative. The inconvenience (the indefinite perception) that went together with focusing on the metropolis and chaos became terrifying, especially when the buildings became reality. That means it is not necessary, for the sake of simplifying, to consider the phenomenon as denial or negativism: it is the distorting mirror of the eighties from France to the United States. It is just an embarrassing self-reflection of the world that has fallen apart, that has lost its centre, that is without 'grand narration': it is the adequate manifestation of the era and it cannot offer a way out or an alternative. This kind of postmodernity, the decades beyond 'rationality', including architectural postmodernism, is not easily understood: it has overstepped the boundaries of comprehensibility. Look at the insanity and chaos of William Burroughs: his 'cutting-up' and 'folding-in' techniques made a new complexity from the pieces of the already written texts. In the age of 'postmemory' ${ }^{11}$ when there is no personal experience, no real but manipulated traces from the past, architecture is also manipulating these layers of history by transforming them from the condition of latency to 'presence', by building a heterogeneous and layered system of different pasts. These pasts are distorted and deformed to be given new meanings in other times, in a new context.

Now we can see clearly that abstracting always needs a previously constructed system. Thus deconstruction 'always posits an orthodoxy which it "subverts", a norm which it breaks, an assumption and ideology which it undermines', said Charles Jencks in 1988. 'And the minute it loses this critical role, or becomes a dominant power itself (as in so many academies), it becomes a tyrannical bore. The same is true of Deconstructionist architecture: it works best as an exception within a strongly defined norm. ${ }^{12}$ ' According to my understanding, which has not much in common with Jencks' postmodern reprimand, a 'strongly defined norm' does not exist anymore: today's aesthetic experience is not normative. It cannot be deduced from reality without the complete and complex relationships of that. There are traces and impressions in the present everywhere, therefore architecture made by deconstructive methods tries to accommodate the topographical, morphological, historical, cultural contexts. It wants to dissolve in this continuous heterogeneity while taking progression into consideration. Asking those questions that Derrida or Peter Eisenman proposed helps us to find our role and meaning in the posthumanic chaos, to have our 'exactly-the-same' forms in the multiplicity of the eighties. But Jencks is right if we are looking on deconstruction as an apparent paradox, since both the existing structure ('pretext') and the operating system ('language') is chosen and built up by the author ('writer-architect'). That is to say the creating process involuntarily becomes arbitrary and individualist. It is obvious that the influence of this author is unavoidable, because an 'analogue response' always has to

14 - ARCC Journal / Volume 5 Issue 2 - 14 
be a personal reading of the story. The paradox is that architectural deconstruction uses the Barthesian principles in order to liberate the oeuvre from the architect while it is making the most individualist 'symbolism': the author is not dead and abstraction is deformed. Finally the pieces of the fallen-apart world are set up in an exact, moreover an ideological construction.

\section{DeFormating Decon}

If we consider 'deconstructivism' as a label stuck on an almost heterogeneous group of independent architects, the boring image would be expressed with great subtlety. In this way architectural theory got to the centre of interest, above all since Derridaian thoughts was transposed into architecture through this principle. The main characters of this transposition were Bernard Tschumi and Peter Eisenman and the importance of studying their activities - notably around 1990 - would seem to be self-evident. Now we have to focus on Eisenman because he integrated another 'conceptual tool', again based upon philosophy, to his experiments and we want to seek for new forms ${ }^{13}$. Transposing folding to architecture appeared to be useful and relevant as a way of solving the cultural-aesthetic problems sketched out earlier in this essay. Of course as with deconstruction it was not just Eisenman who was interested in the topic, and this tendency was made public and canonized by the Architectural Design special issue Folding in Architecture ${ }^{14}$ edited by Greg Lynn ${ }^{15}$ in 1993. If possible, this classification was more diverse than the deconstructive label, Lynn rather presented attempts of interpretations than offered a definite reading of Deleuze. Looked at today, the importance and the level of the writings and projects is very unequal: now only two of the eleven plans seem to be important, not including Eisenman's. ${ }^{16}$ Such variety appeared in the scale of the projects since, according to Lynn, folding wanted to be suitable for furniture designs and regional structural plans. Although it wasn't known where the movement would head for, emphasizing the items in the book gives the precise framework of the 'after-decon era' with images influenced above all by Eisenman and Libeskind: the five emphasized texts have now gained a wider importance than they had at the time.

Deleuze's original extract ${ }^{17}$ was the (philosophical) base and placing it there linked the whole oeuvre of the French thinker to the realm of architecture. This text was used in John Rajchman's

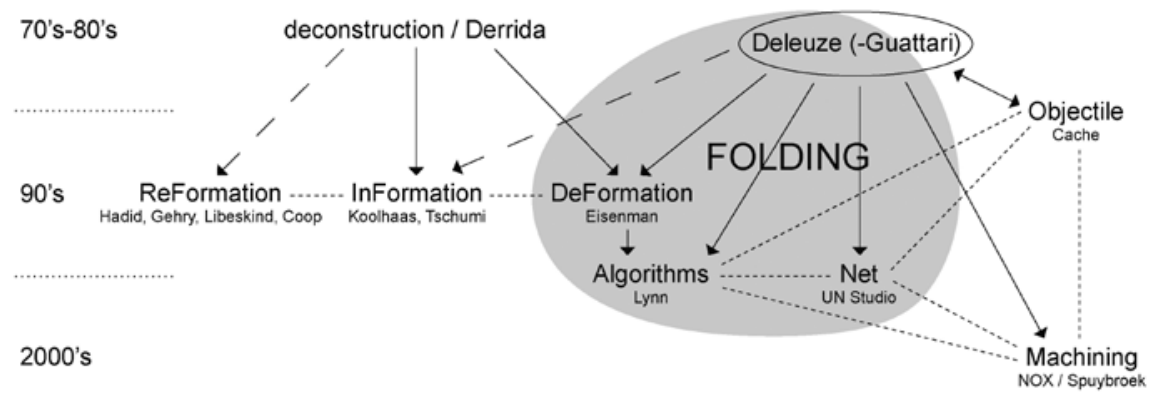

15 - ARCC Journal / Volume 5 Issue 2 - 15 
analysis that would be developed further in other books by him ${ }^{18}$ giving a specific interpretation of the theory, establishing the transposition of it and emphasising on the architectural movement. Peter Eisenman was represented by three 'authentic' folded projects, one of them was the Rebstockpark-plan in Frankfurt, which was supported by the critically acclaimed text, Folding in Time: The Singularity of Rebstock. The also many times, and in many places cited summary of editor Lynn ${ }^{19}$ posits the works in a context that extends from deconstruction to intricate systems with the later increasing an emphasis on mathematic and biological references.

The fifth highlighted article was written by Jeffrey Kipnis whose out of date title Towards a New Architecture enveloped a great 'medical report' about architecture in the early nineties considering especially the legacy of decon. According to him two ways appeared to be feasible to get out of the exhausted collage system. One direction, so-called InFormation, that is based on collecting a graft, 'usually by encasing disparate formal and programmatic elements within a neutral, modernist monolith. The resultant incongruous, residual spaces are then activated with visual layering, programmatic innovation, technological effects and events. ${ }^{20}$ This classification can be understood easily by looking at the purely modernist figures of the buildings of Rem Koolhaas $^{21}$ and Tschumi from the nineties that are transfer the essence of architecture from form (aesthetics) to event. Kipnis's other proposal, DeFormation is about 'grafting abstract topologies [into the program and space] that cannot be decomposed into simple, planar components nor analysed by the received language of architectural formalism. ${ }^{22}$ This way, the direction Eisenman follows, tries to step forward to never-seen complex forms from deconstructive fragments hence it has to refuse the tool of superposition and develop program and figure together. (To be precise and consistent I need to introduce a third group of architects like Zaha Hadid and Frank O. Gehry who continued their quite simple formal experiments. For want of a better term, I call this marking-time ReFormation that is about fulfilling and exhausting the analogue design with digital constructing devices in order to achieve a realization. ${ }^{23}$ )

We have to continue with investigating DeFormation further, not just searching for the new form but rather to 'think architecture beyond complementarity and binarization, beyond subjectivity and signification'24 as Elizabeth Grosz posed the question comparing the philosophical work and the architectural use of Derrida and Deleuze. Such questioning is significant especially because these kinds of battles were fought earlier in non-representative or non-objective arts. The expression in French informel art analyzed by Deleuze (and its American counterpart, action painting, by Rosalind Krauss ${ }^{25}$ ) rivalled abstract constructions as 'hard edged' collage-movements for finding a new role for the author, trying to answer the problem of form-giving and processing, and even getting rid of restrictive tradition while resisting capitalism and consumerism. Francis Bacon was one of the few artist whose paintings were neither representative/objective nor abstract. This singularity was underlined by Deleuze ${ }^{26}$ : the blurred and distorted, familiar and yet at the same time strange bodies were floating in a recipient space. Such unlimited, contourless 'figurativeness' has indefinite flesh, no skeleton, it is dissolving as much in the inner space of the painting as outside of the frame, while the body still has an immanence. Folding in architecture attempted to behave in just this way. 


\section{Deleuze-4-ever}

'As is always the case in architectural design theory, DeFormation is an artifact, a construction of principles that have emerged after the fact from projects by diverse architects that were originally forged with different intentions and under different terms and conditions. ${ }^{27}$ Contrary to the architectural deconstruction that was canonized after taking shape slowly and 'just at the moment when literary intellectuals are jumping off... the Deconstructivist bandwagon'28, architectural folding emerged in the same year as the English translation of Deleuze's Folding-book, therefore it did not have a long history. Conversely it is true that the oeuvre of Deleuze is coherent and extensive from the seventies and 'le pli' appeared much earlier at least in Leibniz's work ${ }^{29}$. All the reasons and processes mentioned above contributed to see the universe folded from folds: unifying all the systems, creating new memory-politics, mediatising societies, formal questions directed at smoothening, ending 'post-everything'. Considering time as a moment dependent on chance introduces the events to 'weak aesthetic experience'30. 'Architecture can no longer be bound by the static conditions of space and place, here and there. In a mediated world, there are no longer places in the sense that we used to know them. Architecture must now deal with the problem of the event. ${ }^{31}$

Now we need to see what the intentions, purposes and means of folding were around 1993: how did the theory and design process try to exceed or smoothen decon? Architectural event can be a keyword as it was with InFormation but here event wants to be integrated into the structure, it is not satisfied with residual spaces. Decon let the event happen by confronting human movement with disjunctive space, within a static collage, folding made it happen as it permitted structure to be influenced by event. This sort of event is heterogeneous and it contains chaos in contrast to decon that was facing up to chaos. The former was then 'dissolving' the latter was a kind of 'resistance'. In decon, interstitial meant the existence of something in between worlds, shifted into flowing worlds, into the fluidity of interstitial, into 'milieu' as Deleuze called. More than anything else, the notion of rhizome explains this complexity, to see the world as a non-hierarchical, net-like multiplicity. Rhizome is the milieus that contain each other mutually, and it is not a copy, rather it is a kind of map, a universal metaphor. In its background, as we will see it later ${ }^{32}$, there is philosophy, literature, neurology, biology.

While Derrida was originally investigating only the closely related realms of knowledge that are philosophy, literature and language, Deleuze was truly interdisciplinary as expanding his theory or letting it be influenced by art (Baroque, Bacon, cinema ${ }^{33}$ ) and science. As re-evaluating the oeuvre of Freud, deconstruction was itself one of the indicators, Deleuze exchanged the Derridaian psychoanalysis to a 'schizoanalysis' that could better describe and understand the condition of our schizoid era ${ }^{34}$. Besides these Deleuze merged architectural references and spatial relevance into his theory contrary to the nonspecific deconstructive thoughts. The early research of Bernard Cache and their teacher-student relationship helped to expound on the theory of the frames and images that define 'interstitiality'. ${ }^{35}$

Mark Wigley was accompanying decon along its history in architecture ${ }^{36}$ so as Rajchman was doing with folding. Hence in 1993 Rajchman just wrote an introduction, waiting for the results of being transposed from philosophy. They did not overrate the historical relationships of each

17 - ARCC Journal / Volume 5 Issue 2 - 17 
movement: in the case of deconstruction universality of modernism and constructivism was considered as the base of the critiques both theoretically and formally, while on the other hand, Baroque was the first era that tried to be 'not divided up by sets of discrete elements'37, to find the world continuous. This is one of the reasons why decon was constructed from discrete elements into a unity by superposition, and why folding was a process with continuous operations into a diversity by superimposition as Eisenman called it. After 1990 it was necessary to get over the fact that we had been dissecting the classical old problems of modernity before. This kind of critique needed to be exceeded because universality and homogeneity did not mean a perspective anymore, and neither did the collaged, built-up-from-pieces heterogeneity. The previously mentioned graft could have been an alternative technique to superposition: it creates heterogeneity while it makes efforts to cooperate with and keep together the parts instead of emphasizing incoherence and contradiction. It wanted to result in the complexity of Deleuze which of course differs from the notion of Venturi's postmodern ${ }^{38}$. As we saw in the paintings of Bacon folded systems and forms are blurred into a seamed whole, rather than edged seamlessly as in decon: the former hides all initial elements, the latter leaves them intact in the collage. In the same way that the pictures did not want to become representative or personal, folded architecture tried to escape from expressionism by the means of the so-called 'informelity'39, contrary to decon's investigated personal formality. The eighties' simultaneity of figure and ground ${ }^{40}$ created a smoothened into a rhizomatic, continuous space without inside and outside (Vidler referred to it as 'death of object') but with an integrated 'interstitiality'. Thus it is obvious that as decon's heterogeneity stressed morphology folding's homogeneity preferred topology, the act of movement or material heterogeneity rather than the heap of ruins or formal rupture.

Decon was born in a Cartesian world: its thinking and form was based on the modern tradition of Euclidean geometry that appeared in the limited and rigid structure of a grid that is constructed from points. The fluid notion of folding is embodied in a geometry that tried to move away from Euclid, tried to be 'anexact' or so-called 'pliable' and its assumed shape is an infinite surface from folds. Therefore the space of folding is curved or curvilinear in contrast to decon, which is angular and rectilinear. If the latter was atectonic in the meaning of dislocating the traditional elements of buildings like columns or walls, then the former should be 'hypertectonic': it superseded the historical structural-tectonic systems, it wants to be independent from gravity and the duality of vertical and horizontal but it still needs to be constructed in a kind of regular way.

\section{Non-folded architecture}

Michael Speaks in the foreword of Earth Moves asks whether the shift from 'deconstructivist' forms to folded forms should have been qualified as new. ${ }^{41}$ It is obviously an important problem but it cannot be the main issue if we are focusing on the relationship between architectural theory, cultural history, and the history of media and information technology. Mario Carpo has this focus when he writes about that it was partially a fortunate coincidence of the intention of folding to smoothen the fragmented and rigorous forms of decon and the rapid spread of computers, and what is more, he affirmed, the process was fertilized by the continuity-theory of 
Deleuze. But the declared 'folding movement' in architecture did not become readily established thanks to another coincidence of paradigmatic and historic facts ${ }^{42}$.

As I have mentioned, in 1989 the Promised Land of liberal democracy penetrated nearly the whole world but it was not calculated at that time that a kind of balance, in other words a cold war, guaranteed the holding back of capitalism/globalism. After a few years it realized that without alternatives or even utopias there is nothing more than global capitalism gone out of control repressing cultures and local identities ${ }^{43}$. Changes were quite fast in the historical-political-economical scene, and architecture kept pace: the prompt killing of decon was succeded by the quick demise of folding in a five years period. The later death was also quickened by the essence of the movement itself, inasmuch as it was still a very conceptual idea. In the years that followed 'simple chaos' and elitism, after the postmodern state and philosophy itself, including deconstruction in this way, there was nothing in the background: the system had come to an end. Such single abstract or conceptual issues like folding were not able to survive those changes or the absence of 'grand paradigms/narratives', or rather the slippery plurality.

Practical-technical problems also emerged as for example in the case of Lynn's Presbyterian Church building in New York, the so-called 'deconstructed blob', that has not much in common with the original idea after its completion in 1999. It underpins Kipnis' contrast between the much higher rate of realization for InFormation and the hypothetical attribute of DeFormation ${ }^{44}$. Because of this theoretical character the multiplicity of folding gives another apprehension whether there is no technique to include all the complexities in the world to a certain 'project'. Though Lynn and others tried to link principles like René Thom's chaos-theory or the results of biological researches into their systems, complexity would not be under their control: it is much more "perplicated' but to understand it ${ }^{45}$.

\section{BAD diagrams}

Now, if we see the universe as continuous, and also acknowledge that designing methods have gained extreme significance, it is obvious to consider architectural theory over at least the last few decades as the history of the diagram. Then the phenomenon of diagram is more than pure geometry, research, illustration, structure, or the superposition of these - but rather the totality and essence of all. It is a medium, a device between anteriority, interiority and exteriority (using Eisenman's notions): diagram is a mirror that shows, but not represents, the process of design. In this way it could be a kind of theoretical tool but exactly the shift from 'pure forming' to the entire 'economy of architectural production' makes it an all-encompassing medium. As it is a tie it helps theory to get closer to practice, to unify author and work or even to link any discipline into design. Folding is a kind of diagram and it has a key position in the diagram's system as it widened the realm at the same time as tightening the link between the elements of the realm. All the above-mentioned architects, artists and theorists created their own notion of the diagram, differing from each other in only minor ways. Foucault, Bacon, Deleuze, Eisenman, Lynn, and UN Studio have an interpretation of this designing manner and although it would be necessary we cannot go into them in this paper.

Folding did not fully replace decon but enlarged it, literally smoothened the method and made

19 - ARCC Journal / Volume 5 Issue 2 - 19 
it more sensitive to contexts. As the neutral museum or the white cube lost their significance with the exodus of art from them, giving importance to the city, nature and event, architecture also refused to correspond to a surface-like context and it focused on the event. Thus folding transformed both figure and ground, making a shift towards non-analogue thinking. The traditional analytical-critical device nearly turned into a generative one, concerning both the design process and the author. Conventional contexts started loosing their dominating, repressing position in the architectural creation but not by erasing themselves nor by the postmodern 'genius loci' growing rich in meaning. There were other, latent, contexts that came in, in fact all contexts tried to come in that resulted in the built environment becoming just one input data of diagram. So the folding technique was considered as semi-digital if architecture, architect and building became a part of the network-system and the input data did not remain a single parameter. The latter means that the parameters, all changing quantities are unfolded into discrete numerals of the diagram that creates a complexity. ${ }^{46}$

However it entails a critique since this model turned into the manifest of global capitalism instead of criticizing it. From this position two questions emerge for BAD diagrams: do we accept the network-system and analyse it to see where to head for and reach, or turn against it to resist? It is a very important issue if we cite again a distinction between decon and folding: decon tried to manage a kind of autonomy of the whole architectural paradigm, whether in a declared way or not, but folding wanted to assimilate. Both happen with buildings among contexts (as built and latent environments), architecture among disciplines (beyond interdisciplinarity), architect among experts (observers and designers of structures). I have to emphasize the significance of Marc Augé's Non-lieus ${ }^{47}$ sans identity and Derrida's Mal d'archive ${ }^{48}$ sans memory, with no comment. Rather I cite the text which this essay began: 'Illusion implies a process, and that this process is oriented to a certain end. In this sense, the project of Enlightenment, the basis of modernity, still participates in a secular theism, in the idea that it is possible to discover an absolute reality, within which art, science, and social and political practice can be constructed on the basis of universal rationality. When this system enters into crisis (and it does enter into crisis, precisely as a result of the impossibility of establishing a universal system), we find ourselves faced with the real crisis of the modern project and the perplexing - we might say critical - situation of our contemporaneity. ${ }^{49}$

\section{Notes}

1 An attribute of Deleuze, 'a folding through or folding across', see Rajchman, Constructions, 18.

2 Cf, Elizabeth Grosz's statement about the resistance of 'applying' Deleuze's work into any discipline: 'theory is not so much to be applied as to be used'. Grosz, 60.

3 Solà-Morales, 60.

4 This kind of liberation made two parts of the world, but those parts were not similar to the previous parts existed before 1990. The so-called developed, highly industrialized or just developing countries are getting over postmodernism, while the rest of the world, stepping forward from third position to the second, remains on the periphery in the condition of a premodern state. To clearly understand this problem of 'internal duality' see for example the artworks of William Kentridge.

20 - ARCC Journal / Volume 5 Issue 2 - 20 
5 This notion of Francis Fukuyama's (The End of History and the Last Man. London: Penguin Books, 1992) means that liberal democracy has conquered the world, beaten monarchy, fascism, communism and homogenized (or it is homogenizing) all systems. Therefore it is the endpoint of governing and the ideological development of men. Cf. with its critique of Derrida (Specters of Marx, New York \& London: Routledge, 1994).

6 Kipnis, $A D$ 102, 42.

7 Kipnis, $A D$ 102, 42.

8 Mario Carpo: Architecture in the age of pliancy. In: Architecture d'Aujourd'hui 349, Nov-Dec. 2003, 102. Carpo cited Wolfgang Köhler, a psychologist and his 1929 experiment that examined angular and round shapes, associated with created arbitrary names: 'taketian' and 'malumian'.

9 The Omnibus Volume, the cataloguing of 'deconstructive movement' studied the paradigm's philosophical and architectural references, the relationship with Russian constructivism, and dealt with such artworks as those of Anselm Kiefer, Valerio Adami or Gordon-Matta Clark. But it has to be noted that adapting deconstruction to art is not a declared act and an underpinned fact.

10 Contrary to this, postmodernism rejected modernism and abstraction while it was reconsidering tradition loudly. The situation, of course, was not that black and white since the main architectural theorists of the decade (Colin Rowe, Christopher Alexander, Christian Norberg-Schulz, Aldo Rossi) have a plurality in thinking and they had a great influence on certain directions of architectural deconstruction.

11 Marianne Hirsch: Family Frames. Photography Narrative and Postmemory. Cambridge: Harvard University Press, 1997.

12 Charles Jencks: Deconstruction: The Pleasures of Absence, in: Omnibus Volume, 120.

13 Tschumi was building the La Villette Park in Paris at the time and published his early writings and a brand-new book on 'urban events' partly following his previous researches: Architecture and Disjunction: Collected Essays 1975-1990. Cambridge: MIT Press, 1994 and Event-Cities series vol.1, Cambridge: MIT Press, 1994.

14 As the paper was published by Academy Editions, London and the editor is Andreas Papadakis again, the comparison with the deconstructive debut in 1988 goes without saying.

15 This publication with editing the issue was the coming-out of Lynn as well. He graduated from Miami University of Ohio in 1986 and he got an M.ARch. from Princeton in 1988. In 1992 he published 'Multiplicitous and In-organic Bodies' in Assemblage 19, later republished in Folds, Bodies \& Blobs and he was a co-editor of The Fetish, Princeton Architectural Press (with Edward Mitchell and Sarah Whiting).

16 These are Lynn's Stranded Sears Tower and Reiser+Umemoto's Croton Aquaduct (under the name of 'RAA Um' including Stan Allen). It also has to be mentioned that both Jesse Reiser and Nanako Umemoto studied at Eisenman's Cooper Union and Institute for Urban Studies in New York. Polarizing and simplifying: amongst others, furniture plans and a 'usual-project' appeared from Frank Gehry. One project was shown from Thomas Leeser who had just left Eisenman's office after several years working with him. Two buildings were presented and talked much about in the critical writings by Bahram Shirdel who studied at Cranbrook Academy of Art under Daniel Libeskind (as Reiser+Umemoto), taught two years at Harvard with Eisenman and Kipnis, then at AA with Kipnis, then disappeared in Iran. Henry Cobb's ordinary tower was the only built project. Chuck Hoberman is rather a sculptor and a toy-developer. Stephen Perella was not yet able to come out with a significant achievement (see: Hypersurface Architecture. Architectural Design 68, ed: Stephen Perrella, 1998).

17 The Fold - Leibniz and the Baroque: The Pleats of the Matter, 16-21.

18 Constructions and The Deleuze Connections (Cambridge, Ms: MIT Press, 2000).

19 Architectural Curvilinearity: The Folded, The Pliant and the Supple, also published in Fold, Bodies \& Blobs.

20 Kipnis, $A D$ 102, 43.

21 The OMA/Koolhaas also uses a kind of folding that has significance in relieving hierarchy and making the space fluid. The plans of Jussieu Library, are a case in point, with its continuously sloping slabs and the spatial complexity that it results. At the same time it should be noted that this simplifying intention leads to the aesthetic degrading, to using up folding. Another connection between Koolhaas and Deleuze is the interpretation of Foucault's panopticon (see the project of Arnhem Prison).

21 - ARCC Journal / Volume 5 Issue 2 - 21 
22 Kipnis, $A D$ 102, 43.

$23 \mathrm{Cf}$, Hani Rashid: Morphing the Sublime. In: Metamorph 9. International Architecture Exhibition. Focus Fondazione La Biennale di Venezia, 2004

24 Grosz, 59.

25 See her books: The Originality of the Avant-Garde and Other Modernist Myths (Cambridge, Ms: MIT Press, 1985) and The Optical Unconscious (Cambridge, Ms: MIT Press, 1993) and compare for example the abstract expressionism of Jackson Pollock and the intuitive experiments of Coop Himmelb(l)au. It also has to be mentioned that Krauss positioned Eisenman's work in this context ('Death of a Hermeneutic Phantom: Materialization of the Sign in the Work of Peter Eisenman' In Peter Eisenman's Houses of Cards, New York: Oxford University Press, 1987, 166-184), as she integrated Derrida's grammatology-theory with her critical practice to attack the autonomy of art.

26 Francis Bacon: Logique de la Sensation. Paris: La Différence, 1981. See also Rajchman's interpretation in the chapter 'Abstraction' in his Constructions.

27 Kipnis, $A D$ 102, 44.

28 David Lodge: A Review of the Tate Gallery Symposium in Omnibus, 90.

29 The notion of 'le pli' appeared first at Deleuze in his book of Foucault (Paris: Minuit, 1986, and Minneapolis: University of Minnesota Press, 1986).

30 Solà-Morales regarded the pli-theory (from the French Foucault-book of Deleuze) as one of the significant pillars of 'weak architecture' as a penetrating program to understand reality of today (the cited essay was written in 1987 but published in English in only 1996).

31 Peter Eisenman: Unfolding Events: Frankfurt Rebstockpark and the Possibility of a New Urbanism (1991). In: Written into the Void, 13.

32 Dozens of notions of Deleuze will be used in architecture in the nineties for example as a designing tool (Eisenman's mapping) or formal-structural relevance (Lynn's biological figures).

33 Cinema 1. The Movement-Image (Minneapolis: University of Minnesota Press, 1986. trans. Hugh Tomlinson, Barbara Habbersam) and Cinema 2. The Time-image. (University of Minnnesota Press, 1989. trans. Hugh Tomlinson, Roberta Galeta).

34 See the two-volume Capitalisme et Schizophrénie of Gilles Deleuze and Félix Guattari: L'Anti-CEdipe (Paris: Minuit, 1973) and Mille Plateaux (Paris: Minuit, 1980).

35 Cache sees architecture as the 'art of the frame' connecting furniture with the outer world: this kind of folding was written down in his Terre Meuble around 1983 and cited by Deleuze in 1988. So it was part of the AD-issue but in a latent manner and of course after the breakthrough of the movement it was immediately published in English, further reinforcing the architectural relevance of it. It was the first item of ANY's Writing Architecture series that underlies its significance. Here we cannot dwell on the theme 'objectile' of Cache and Deleuze although it is an important base of non-standard theory.

36 From the MOMA-show to the The Architecture of Deconstruction: Derrida's Haunt. Cambridge, Ms: MIT Press, 1997.

37 Rajchman, $A D$ 102, 60.

38 See the different historical analyses of postmodernism and folded complexity at Lynn (AD 102, 8), Rajchman (Constructions, 17), Jencks (Post-Modernism and the Revenge of the Book, 189).

39 See Anthony Vidler's excellent comparison of the 'biotechnological informe' of Lynn and Tschumi's informe based on Bataille (Vidler, 227).

$40 \mathrm{Cf}$, the oeuvre of Eisenman.

41 Earth Moves, xiv-xv.

42 Cf, new prefaces by Carpo in the reprint of AD 1021993 (London: Wiley and Sons, 2004) and symposium Twelve Years of Folding - Deleuze and the IT-Revolution in Architecture (21 May 2005, MAK, Wien) with the declared purpose to investigate the hegemony of the mathematics of calculus in the technological environment of the time and the first formal avatars of the digital revolution in architectural design with eg. Stan Allen, Carpo, Eisenman and Lynn.

22 - ARCC Journal / Volume 5 Issue $2 \quad-22$ 
43 Mark C. Taylor: The Moment of Complexity. Emerging Network Culture. Chicago: The University of Chicago Press, 2001.

44 Kipnis, $A D$ 102, 48.

45 Cf, main critiques of UN Studio's work.

46 This idea has not much in common with the theory of Kas Oosterhuis and Marcus Novak whose premise says let technology (actually digital or nano) into architecture.

47 Marc Augé: Non-places. Introduction to an Anthropology of Supermodernity. Transl: John Howe, London - New York: Verso, 1995.

48 Jacques Derrida: Archive fever. A Freudian Impression. Transl: Eric Prenowitz, Chicago: The University of Chicago Press, 1995.

49 Solà-Morales, 59.

\section{Sources}

Cache, Bernard: Earth Moves: The Furnishing of Territories. Cambridge, Ms: MIT Press, 1995.

Cache, Bernard: Inflection as Gaze. In: Territorial Investigations. Ed.: Anette W.Balkema and Hank Slager. Amsterdam/ Atlanta: Rodopi, 1999. 23-40.

Carpo, Mario: Architecture in the Age of Pliancy. In: Architecture d'Aujourd'hui 349, Nov-Dec. 2003, 102-103

Deconstruction - Omnibus Volume. Ed: Andreas Papadakis, Catherine Cooke, Andrew Benjamin. London: Academy Editions, 1989.

Eisenman, Peter: Written into the Void. Selected Writings, 1990-2004. New Haven and London: Yale University Press, 2007.

Eisenman, Peter: Diagram Diaries. New York: Universe Publishing, 1999.

Folding in Architecture. Architectural Design Profile 102, ed: Greg Lynn, 1993.

Grosz, Elizabeth: Architecture from the Outside. Essays on Virtual and Real Space. Cambridge, Ms: The MIT Press, 2001.

Harris, Paul A.: To see with the Mind and Think through the Eye: Deleuze, Folding Architecture, and Simon Rodia's Watts Towers. In: Deleuze Connections. Deleuze and Space. Ed: Ian Buchanan and Gregg Lambert. Edinburgh: Edinburgh University Press, 2005. 36-60.

Jackson, Mark: Diagram of the Fold. The Actuality of Virtual Architecture. (2001) http://www.ifib.uni-karlsruhe.de/web/ ifib_dokumente/downloads/mark_jackson.pdf

Jencks, Charles: Post-Modernism and the Revenge of the Book. In: This is not Architecture. Media Constructions. ed. Kester Rattenbury. London-New York: Routledge, 2002. 174-197.

Lootsma, Bart: The Diagram Debate, or the Schizoid Architect. Archilab 2001, ed: Marie Ange Brayer ans Béatrice Simonot. Orléans: Mairie d'Orléans, 2001.

Lynn, Greg: Folds, Bodies and Blobs: Collected Essays. Bruxelles: La Lettre vole'e, 1998.

Lynn, Greg: Animate Form. New York: Princeton Architectural Press, 1999.

Rajchman, John: Constructions. Cambridge, Ms: The MIT Press, 1998.

Solà-Morales, Ignasi de: Weak Architecture. In: Differences: Topographies of Contemporary Architecture. Cambridge, Ms: The MIT Press, 1996.

Spuybroek, Lars. NOX: Machining Architecture. London: Thames \& Hudson, 2004.

UN Studio (Ben van Berkel - Caroline Bos): Diagrams. Interactive instruments in operation. In: This is not architecture. Media Constructions. ed. Kester Rattenbury. London-New York: Routledge, 2002. 99-109. First published in ANY 23, ed. Cynthia C. Davidson, guest eds. Ben van Berkel and Caroline Bos.

UN Studio (Ben van Berkel - Caroline Bos): Move. 1 - Imagination. 2 - Techniques. 3 - Effects. Amsterdam: UN Studio \& Goose Press, 1999.

UN Studio (Ben van Berkel - Caroline Bos): UN Studio. UN Fold. Rotterdam: NAi Publishers, 2002.

Vidler, Anthony: Skin and Bones. Folded Forms from Leibniz to Lynn. In: Warped Space. Cambridge, Ms: The MIT Press, 2000. 219-234.

23 - ARCC Journal / Volume 5 Issue 2 - 23 